\title{
Early Detection of Chilling Injury with Fourier Transform Infrared Spectroscopy
}

\author{
J. George Buta and Chien Y. Wang \\ Horticultural Crops Quality Laboratory, Beltsville Agricultural Research \\ Center, Agricultural Research Service, U.S. Department of Agriculture, \\ Beltsville, MD 20705
}

\section{Additional index words. Cucurbita pepo, storage, temperature preconditioning, zucchini squash}

\begin{abstract}
Fourier transform infrared (FTIR) spectroscopy detected early large increases in fluid leakage from zucchini squash (Cucurbita pepo L.) subjected to a chilling temperature (5C). The increase in fluid leakage (principally water) was found after 1 day at 5C, while surface pitting was detected only after 3 days of storage at 5C. Prestorage temperature conditioning at $15 \mathrm{C}$ for 2 days greatly diminished the fluid leakage measured by FTIR spectroscopy after 1 day of storage at 5C. Measuring fluid leakage using FTIR spectroscopy seems to be a promising technique to detect the early onset of chilling injury.
\end{abstract}

Certain fruit and vegetables are injured when they are stored at low, nonfreezing temperatures. Critical threshold temperatures for this chilling injury $(\mathrm{CI})$ are 10 to $13 \mathrm{C}$ for most tropical and subtropical crops and 5 to $10 \mathrm{C}$ for some temperate-zone crops (Hardenburg et al., 1986). Exposing chilling-sensitive commodities to temperatures below the critical range causes cellular breakdown and loss of membrane integrity. These injuries lead to increased membrane permeability, ion and solute leakage, and exudation of cellular fluid into the intercellular spaces (Lyons, 1973). If the chilling continues, more symptoms develop, including a water-soaked appearance, surface browning and pitting, metabolic dysfunction, and tissue collapse (Paull, 1990). CI severity usually is evaluated by inspecting visual symptoms. Unfortunately, this type of inspection usually only detects changes once they are irreversible; thus, it is too late to use postharvest treatments, such as intermittent warming, to reduce CI (Hatton, 1990). Therefore, an early CI indicator would be useful, particularly for situations in which the changes are reversible.

Ion or solute leakage does not seem to be a reliable indicator of $\mathrm{CI}$ in early stages of symptom development after exposure to chilling temperatures, because, in some crops, no increase in electrolyte leakage is found (McCollum and McDonald, 1991; Murata and Tatsumi, 1979). In an attempt to develop another technique to detect CI early, we investigated using Fourier transform infrared (FTIR) spectroscopy to determine whether changes in membrane integrity could be detected. FTIR spectral measurements can be done rapidly

Received for publication 7 Aug. 1992. Accepted for publication 9 June 1993. The cost of publishing this paper was defrayed in part by the payment of page charges. Under postal regulations, this paper therefore must be hereby marked advertisement solely to indicate this fact. and accurately over the whole infrared spectrum and can be done with intact cells (Sows et al., 1991) and membrane fractions (Mantsch et al., 1986).

The zucchini squash used for this study were freshly harvested from a local farm in Beltsville, Md. Samples were selected by size $(20 \pm 2 \mathrm{~cm}$ long) and divided randomly into three groups. The first group was placed at a chilling temperature $(5 \mathrm{C})$ and the second group at a nonchilling temperature (15C). The third group was preconditioned at $15 \mathrm{C}$ for 2 days, then transferred to $5 \mathrm{C}$. Three fruit from each treatment were used for daily FTIR spectral measurements.

A cylinder (1 $\mathrm{cm}$ in diameter) was removed from each zucchini $6 \mathrm{~cm}$ from the blossom end within $2 \mathrm{~h}$ after the squash were removed from controlled-temperature storage. Disks of cortex tissue $(1 \mathrm{~cm}$ in diameter and $0.25 \mathrm{~cm}$ thick) were cut from just below the surface layers. Fluid leaking from the disks was deposited on the surface contacting the two KRS-5 disks $(13 \times 2 \mathrm{~mm})$ and used for the FTIR spectral measurements. The same procedure was used throughout the experiment. The FTIR spectra were obtained with an FTIR spectrometer (model 60 SX; Nicolet, Madison, Wis.) using a detector (model MCT-A; Nicolet) with a 4$\mathrm{cm}^{-1}$ wave number resolution. Spectra were obtained by averaging 32 scans. Difference spectra were produced from sample spectra by subtracting the disk background. Three difference spectra from the three fruit are shown superimposed in each portion of the figures. A spectrum of water was run with the same system for comparison.

Although no visible effects of the chilling temperature were observed on the zucchini after 1 day, there was significant fluid leakage from the cortical tissue of the chilled zucchini (Fig. 1, top) compared to almost no leakage from the cortical tissue of nonchilled zucchini (Fig. 1, bottom). Fluid leakage was compared by examining the magnitude of absorbance at
1620 and 3200 to $3500 \mathrm{~cm}^{-1}$ wave numbers (Table 1).

Fluid leakage from zucchini was measured after 3 days of storage in chilling temperatures. There was a large amount of leakage from the zucchini kept at chilling temperatures and less leakage from the zucchini stored at $15 \mathrm{C}$ for the same period (Fig. 2, middle). When zucchini were preconditioned for 2 days at $15 \mathrm{C}$ before being placed in the chilling temperature for 1 day, leakage was similar (Fig. 2, bottom) to that found after 3 days of storage at 15C (Fig. 2, middle). Statistical analysis of the areas of absorbance peaks at 1620 and $3400 \mathrm{~cm}^{-1}$ wave numbers confirmed these observations (Table 1). In comparison, the FTIR spectrum of water contained major absorption maxima at 1620 and 3200 to 3500 $\mathrm{cm}^{-1}$ wave numbers (spectrum not shown). Additionally, weak absorption at $2100 \mathrm{~cm}^{-1}$ wave number was found in the water spectrum and the spectra of various other fluid samples (data not shown).

The onset of CI in zucchini also was observed visually. No surface pitting was detected until the third day of storage at $5 \mathrm{C}$.
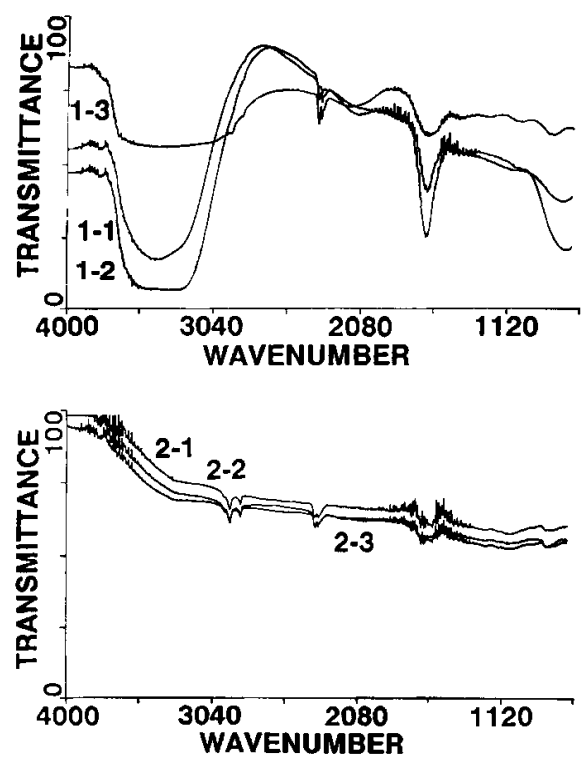

Fig. 1. Fourier transform infrared spectra of fluid leakage from zucchini disks (top) after 3 days of storage at 5C (1-1, 1-2, 1-3) and (bottom) after 1 day of storage at $5 \mathrm{C}(2-1,2-2,2-3)$.

Table 1. Fluid leakage from zucchini cortex tissue after storage at chilling (5C) or nonchilling (15C) temperatures.

\begin{tabular}{lccc}
\hline & & \multicolumn{2}{c}{ Fluid leakage $^{\mathrm{z}}$} \\
\cline { 3 - 4 } $\begin{array}{l}\text { Storage } \\
\text { duration }\end{array}$ & Temp & \multicolumn{2}{c}{ Wave no. } \\
\cline { 2 - 4 } (days) & $\left(\mathrm{cm}^{-1}\right)$ \\
\hline 1 & 5 & 5400 & 1600 \\
1 & 15 & $0 \mathrm{~b}$ & $1.6 \mathrm{~b}$ \\
3 & 5 & $48 \mathrm{a}$ & $5.4 \mathrm{a}$ \\
3 & 15 & $23 \mathrm{~b}$ & $2.5 \mathrm{~b}$ \\
2,1 & 15,5 & $14 \mathrm{~b}$ & $2.1 \mathrm{~b}$ \\
\hline
\end{tabular}

zFluid leakage $=$ Fourier transform infrared absorbance - peak area (in square millimeters).

'Mean separation by Duncan's multiple range test at $P \leq 0.05$. 

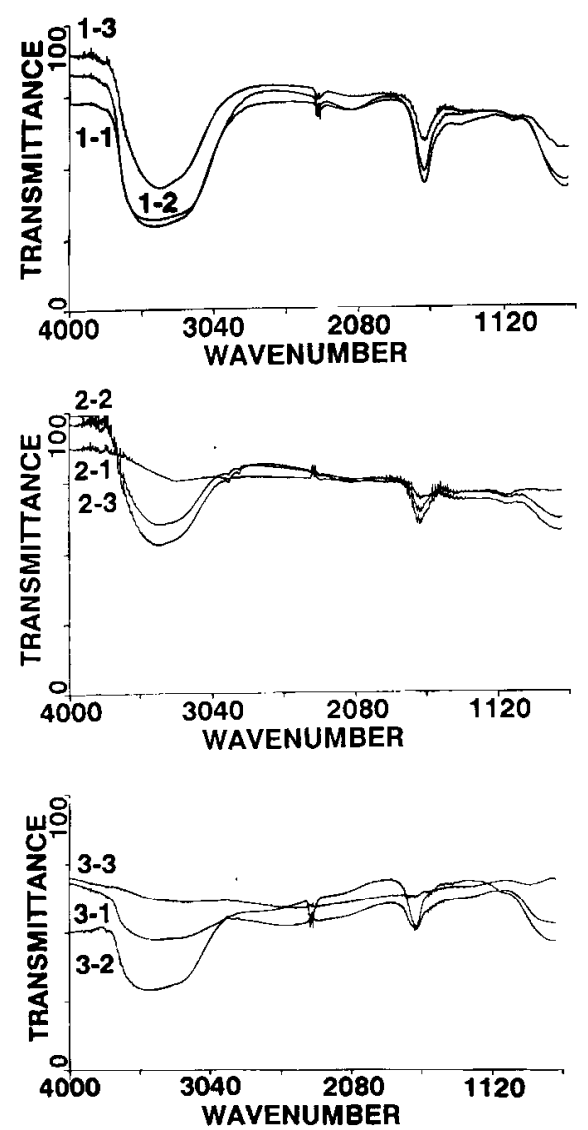

Fig. 2. Fourier transform infrared spectra of fluid leakage (top) after 3 days of storage at $5 \mathrm{C} \mathrm{(1-1,}$ 1-2, 1-3), (middle) after 3 days of storage at $15 \mathrm{C}$ (2-1, 2-2, 2-3), and (bottom) after 2 days of storage at $15 \mathrm{C}$ followed by 1 day of storage at $5 \mathrm{C}$ (3-1, 3-2, 3-3).

Thereafter, CI severity increased with longer exposure duration. Preconditioning zucchini for 2 days at $15 \mathrm{C}$ delayed CI symptom development. These results were similar to those of a more-detailed study (Kramer and Wang, 1989).

A large amount of fluid leakage from the chilled zucchini after 1 day of storage at $5 \mathrm{C}$ indicated that membrane integrity was altered to allow the loss of large amounts of water from the cortical cells. This symptom is an early indication of the onset of changes in membrane structure or phase separations in membrane bilayers involved in CI symptom development (Crowe et al., 1989). Leakage was detected before the appearance of surface pitting. The amount of leakage from zucchini after 3 days of chilling was similar to that found after 1 day of chilling, a result indicating that there was no further major increase in cortical cell leakage with prolonged chilling. Thus, these fluid leakage measurements do not differentiate between noninjurious and damaging levels of chilling, but show the increased amounts of fluid leakage due to the effect of chilling. Surface pitting (the result of irreversible injury) after 3 days of chilling may be the result of continued cellular degradation that began after the onset of exposure to 5C. Fluid leakage was not measured earlier than after 1 day of exposure to the two temperatures; therefore, the amount of time needed to observe the enhanced fluid leakage resulting from $5 \mathrm{C}$ storage was not established.

When zucchini were preconditioned for 2 days at $15 \mathrm{C}$ before exposing them to the chilling temperature, the amount of fluid leakage after chilling for 1 day was similar to that from zucchini stored at the nonchilling temperature and much less than that from zucchini chilled for either 1 or 3 days. This result indicates that alteration in the cortical membranes had occurred during the 2 days of preconditioning such that the effect of chilling temperatures on zucchini had been diminished significantly.

Water was the predominant component of the fluid that leaked from the cortical disk membranes during chilling, and no other components could be detected by FTIR spectroscopy. Another technique that studies the mobility of water is nuclear magnetic resonance imaging. A study of water movement in zucchini subjected to chilling temperatures also found an increase in mobility and breakdown of compartmentalization in the cortical area after 3 days of chilling (Wang and Wang, 1992). This result supports the FTIR spectral measurement of increased membrane permeability ascribed to the onset of CI.

Low-temperature-stressed commodities can recover after short exposure to chilling temperatures (Lyons, 1973) only when the chilling-induced changes are reversible. Detecting CI before the changes become irreversible would be useful to help determine the timing of postharvest treatments to reduce CI. Our study shows that FTIR spectroscopy is a promising technique for this purpose.

\section{Literature Cited}

Crowe, J.H., F.A. Hoekstra, L.M. Crowe, T.J. Anchordoguy, and E. Drobnis. 1989. Lipid phase transitions measured in intact cells with Fourier transform infrared spectroscopy. Cryobiology 26:76-84

Hardenburg, R.E., A.E. Watada, and C.Y. Wang. 1986. The commercial storage of fruits, vegetables, and florist and nursery stocks. U.S. Dept. Agr. Hdbk. 66. p. 130

Hatton, T.T. 1990. Reduction of chilling injury with temperature manipulation, p. 269-280. In C.Y. Wang (ed.). Chilling injury of horticultural crops. CRC Press, Boca Raton, Fla.

Kramer, G.F. and C.Y. Wang. 1989. Reduction of chilling injury in zucchini squash by temperature management. HortScience 24:995-996.

Lyons, J.M. 1973. Chilling injury in plants. Annu. Rev. Plant Physiol. 24:445-466.

Mantsch, H.H. and H.L. Casal. 1986. Biological applications of infrared spectrometry. Fresenius Zeitschrift Anal. Chem. 324:655-661.

McCollum, T.G. and R.E. McDonald. 1991. Electrolyte leakage, respiration and ethylene production as indices of chilling injury in grapefruit. HortScience 26:1191-1 192.

Murata, T. and Y. Tatsumi. 1979. Ion leakage in chilled plant tissue, p. 141-151. In: J.M. Lyons, D. Graham, and J.K. Raison (eds.). Low temperature stress in crop plants. The role of the membrane. Academic, New York.

Paull, R.E. 1990. Chilling injury of crops of tropical and subtropical origin, p. 17-36. In: C.Y. Wang (ed.). Chilling injury of horticultural crops. CRC Press, Boca Raton, Fla.

Sowa, S., K.F. Connor, and L.E. Towill. 1991. Temperature changes in lipid and protein structure measured by Fourier transform infrared spectrophotometry in intact pollen grains. Plant Sci. 78:1-9.

Wang, C.Y. and P.C. Wang. 1992. Differences in nuclear magnetic resonance images between chilled and non-chilled zucchini squash. Environ. Expt. Bot. 32:213-219. 